Article

\title{
Optimization of Shift Schedule for Hybrid Electric Vehicle with Automated Manual Transmission
}

\author{
Wenchen Shen ${ }^{1}$, Huilong $\mathrm{Yu}^{2, *}$, Yuhui $\mathrm{Hu}^{1}$ and Junqiang $\mathrm{Xi}^{1}$ \\ 1 School of Mechanical Engineering, Beijing Institute of Technology, 5 South Zhongguancun Street, \\ Haidian District, Beijing 100081, China; goodluckswc@163.com (W.S.); huyuhui@bit.edu.cn (Y.H.); \\ xijunqiang@bit.edu.cn (J.X.) \\ 2 Department of Mechanical Engineering, Politecnico di Milano, via G. La Masa 1, Milano 20156, Italy \\ * Correspondence: huilong.yu@polimi.it; Tel.: +39-02-2399-8456
}

Academic Editors: Michael Gerard Pecht and Ximing Cheng

Received: 22 January 2016; Accepted: 16 March 2016; Published: 19 March 2016

\begin{abstract}
Currently, most hybrid electric vehicles (HEVs) equipped with automated mechanical transmission (AMT) are implemented with the conventional two-parameter gear shift schedule based on engineering experience. However, this approach cannot take full advantage of hybrid drives. In other words, the powertrain of an HEV is not able to work at the best fuel-economy points during the whole driving profile. To solve this problem, an optimization method of gear shift schedule for HEVs is proposed based on Dynamic Programming (DP) and a corresponding solving algorithm is also put forward. A gear shift schedule that can be employed in real-vehicle is extracted from the obtained optimal gear shift points by DP approach and is optimized based on analysis of the engineering experience in a typical Chinese urban driving cycle. Compared with the conventional two-parameter gear shift schedule in both simulation and real vehicle experiments, the extracted gear shift schedule is proved to clearly improve the fuel economy of the HEV.
\end{abstract}

Keywords: hybrid electric vehicle (HEV); automated mechanical transmission (AMT); gear shift schedule; dynamic programming (DP)

\section{Introduction}

To face the challenge of air pollution, dependence on petroleum, and greenhouse gas emissions, research on improving the performance of electric vehicles (EVs) and hybrid electric vehicles (HEVs) to promote the wide range public and private use of them has been conducted for decades. The performance and energy economy of EVs and HEVs are influenced by many factors, such as transmission control strategy [1-3], traffic environments [4,5], road conditions [6,7] and driver behaviors [8,9]. Thus, the powertrain control of HEVs plays an important role in accomplishing objectives such as high energy efficiency and low emissions.

Research on gear shift schedules for conventional vehicles has aroused great interest, since automatic transmission implemented with different kinds of gear shift schedule can directly affect the fuel economy, riding comfort, emissions and safety during a gear shift of the vehicles [10]. For a parallel HEV equipped with AMT, the optimal operating points of a hybrid driveline are determined not only by the power split, but also the gear ratio of the transmission. However, recently, systematic methods to optimize gear shifting schedule for HEVs have been rarely reported [11-13]. Study on HEVs is mainly focused on the power split algorithm between the engine and motor [14-20].

According to the latest literature research, most HEVs are implemented with conventional two-parameter gear shift schedule based on engineering experience [21-24], such as using the throttle opening and vehicle speed or the torque of input shaft and vehicle speed as reference parameters. Besides, a single parameter gear shift schedule is also implemented, which is difficult to improve the 
fuel economy further. The power transmission system of the HEV is very different from the traditional one; it is necessary to do in-depth research on the gear shift schedule of HEV with the conventional gear shift schedule as reference.

The remainder of this work is organized as follows. In Section 2, the detailed model of every concerned component of the powertrain and longitudinal dynamics is developed in MATLAB/SIMULINK. In Section 3, the gear shift schedule problem is formulated as a multi-objective optimization problem with the constraints of degree of frequent gear shift, state of the engine, motor, battery and transmission. The cost function is derived as weighted fuel consumption and emissions, the state variables are: vehicle speed, power split ratio and battery SOC, the control variable is the desired gear. In Section 4, the formulated multi-objective problem is solved with DP, and the fmincon function in MATLAB is employed to speed up the simulation process. In Section 5, an implementable two-parameter gear shift schedule is extracted based on DP and is optimized based on engineering experiences. Simulation results and analysis are presented in Section 6. Concluding remarks follow in Section 7.

\section{Modeling of the HEV}

To guarantee high modularization of each subsystem and improve the generalization of the simulation platform, the powertrain of the HEV is modeled in MATLAB/SIMULINK. Configuration of the simulation platform can be seen in Figure 1, which shows the route of mechanical and electrical connections. The conventional modeling method [25] derives complicated mathematical equations describing the static and dynamic behavior of the system components, in cases where is too complex for the DP algorithm to solve the optimization problem. In order to reduce the computational burden, each module of the model is rationally simplified. The model of the five simplified subsystems including the engine, transmission, motor, battery and longitudinal dynamic of the HEV can be described as follows.

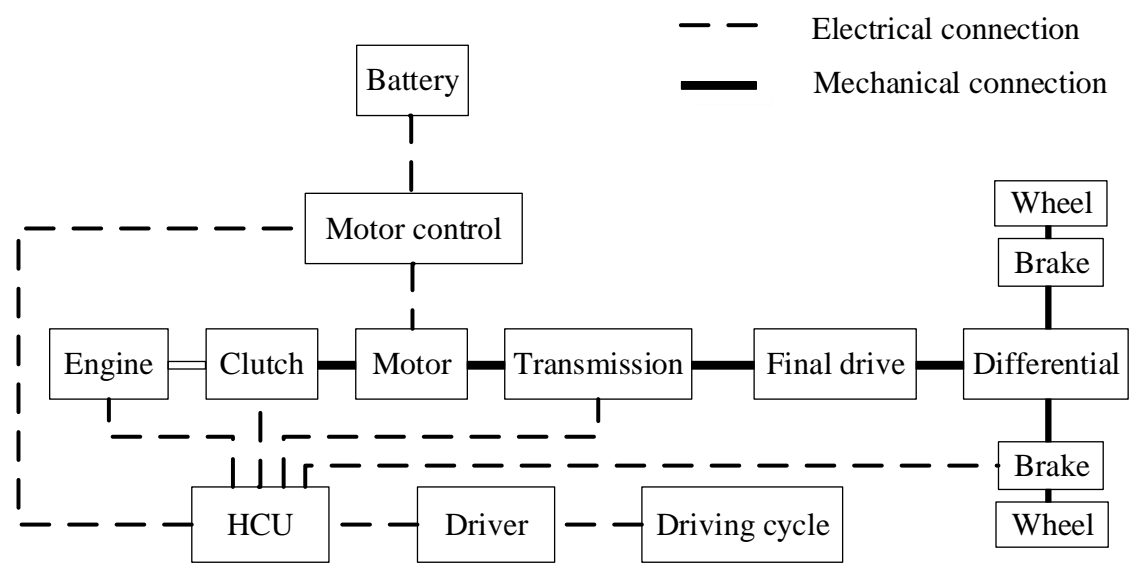

Figure 1. Simulation configuration of the researched HEV.

\subsection{Engine Model}

Dynamic response of the engine is ignored based on quasi-static assumption of the engine [26] so the fuel consumption $\dot{m}_{f, i c e}$, nitric oxide $N O_{x}$, particulate matters $P M$ are only determined by the quasi-static equation of engine speed $\omega_{i c e}$ and engine torque $T_{i c e}$, which can be obtained by the look-up table method. This work assumes that the engine is fully preheated, and temperature of the engine is also ignored. 


\subsection{Clutch Model}

The transmitted torque $T_{\mathcal{C}}$ of the clutch during the three working conditions is expressed as the following piecewise function:

$$
T_{c}= \begin{cases}i_{o} i_{g, t} T_{i c e} & \text { engaged } \\ \frac{4}{3} \mu_{d} R_{c} F_{n} \operatorname{sign}\left(\omega_{c i}-\omega_{c o}\right) & \text { slipping } \\ 0 & \text { disengaged }\end{cases}
$$

where $i_{o}$ is the gear ratio of final drive, $i_{g, t}$ is the gear ratio of gearbox, $\mu_{d}$ is the friction coefficient of the clutch disc, $R_{c}$ is the effective radius of the clutch disc. $F_{n}$ is the normal force of the clutch disc, $\omega_{c i}$ is angular velocity of the input disc of the clutch, $\omega_{c o}$ is the angular velocity of the output disc of the clutch.

\subsection{Transmission Model}

The power lose in different gears is ignored for the simplified transmission, which can be described by

$$
i_{g, t}=i_{G}\left(N_{g, a c t}\right)
$$

where $i_{G}$ is the gear ratio, $N_{g, a c t}$ is the current gear of the transmission.

The actual gear $N_{g, a c t}$ of a two-parameter (throttle opening and vehicle speed) gear shift schedule can be described as

$$
N_{g, a c t}=g(\alpha, v)=\left\{\begin{array}{c}
1 \\
0 \\
-1
\end{array}\right.
$$

where $g$ is the control strategy, $\alpha$ is the throttle opening, $v$ is the vehicle speed, 1 represents upshift, 0 means keep steady, -1 is downshift.

\subsection{Motor Model}

The output motor torque $T_{\text {elm }}$ can be given as Equation (4), and it is unnecessary to describe the electromagnetic process in this research, so only mechanical response and efficiency of the motor is considered. Output torque of the motor is affected by many factors [27], for example, the driver requested motor torque $T_{\text {elm, req }}$, the maximum driving and braking torque at current motor speed $T_{\text {elm }, \text { dis }}, T_{\text {elm,chg }}$, the maximum motor torque when charge and discharge the battery $T_{b a t, d i s}, T_{b a t, c h g}$. $T_{b a t, d i s}$ and $T_{b a t, c h g}$ are determined by the rated charge, discharge power of the battery and current angular velocity of the motor. All the mentioned parameters are comprehensively considered to determine the output torque $T_{\text {elm }}$.

$$
T_{\text {elm }}=\left\{\begin{array}{ccc}
\min \left(T_{\text {elm,req }}, T_{\text {elm }, \text { dis }}, T_{\text {bat }, \text { dis }}\right) & \text { if } & T_{\text {elm,req }}>0 \\
\max \left(T_{\text {elm }, \text { req }}, T_{\text {elm, } \text {, chg }}, T_{\text {bat }, \text { chg }}\right) & \text { if } & T_{\text {elm,req }}<0
\end{array}\right.
$$

\subsection{Battery Model}

The main purpose of this work is to explore the optimal gearshift schedule that minimizing the energy consumption, thus, the effect of temperature and dynamic response are ignored and a static Thevenin model shown in Figure 2 is adopted in this paper [[28]\}. $V_{o c}$ is the electromotive force of the battery package that is measured when no load is attached. $R_{0}$ and $R_{1}$ are series resistance of battery and cables respectively. 


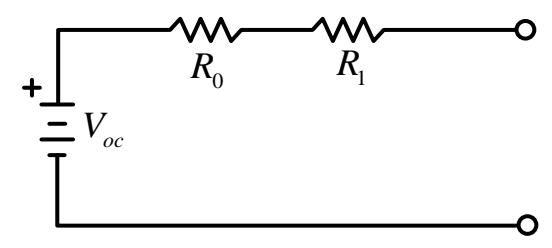

Figure 2. Simplified battery quasi-static circuitry.

The recurrence equation of the State of Charge (SOC) is given as

$$
S O C_{k+1}=S O C_{k}-\frac{V_{o c}-\sqrt{V_{o c}^{2}-4\left(R_{0}+R_{1}\right) T_{\text {elm }} \omega_{\text {elm }} / \eta_{\text {overall }}^{-\operatorname{sgn}\left(T_{\text {elm }}\right)}}}{7200\left(R_{0}+R_{1}\right) Q_{0}}
$$

where $k$ is the time step, $\eta_{\text {overall }}$ is the energy conversion efficiency from motor to battery, $Q_{0}$ is the maximum battery capacity expressed in Ampere-Hours [Ah], $T_{\text {elm }}, \omega_{\text {elm }}$ are torque and speed of motor output shaft at time step $k$.

\subsection{Longitudinal Dynamics of the HEV}

The longitudinal dynamic model is simplified to point-mass model as

$$
\begin{gathered}
m \frac{d v}{d t}=\left(\eta T_{c} i_{g, t} i_{o}+T_{e l m}-T_{w}-T_{r}-T_{b}\right) / r_{w} \\
J_{e} \frac{d \omega_{e}}{d t}=T_{i c e}-T_{c}
\end{gathered}
$$

where $m$ is the mass of the whole vehicle, $\eta$ is the efficiency of the transmission system, $T_{c}$ is the torque transferred by clutch, $i_{o}$ is the gear ratio of final drive, $T_{e l m}$ is torque of the motor, $T_{w}, T_{r}, T_{b}$ are torque of the air resistance, road resistance and braking torque, $r_{w}$ is the radius of the wheel, $J_{e}$ is the engine inertia, $J_{e}$ is the engine inertia, $T_{i c e}$ is output torque from the engine, $i_{0}$ is the gear ratio of final drive, $\eta$ is the efficiency of transmission system.

\section{Problem Formulation of the HEV Gear Shift Schedule}

The state model of the hybrid drive system can be described with discrete recursion equation

$$
\mathbf{X}_{k+1}=f\left(\mathbf{X}_{k}, \mathbf{U}_{k}\right)
$$

where $\mathbf{X}_{k}$ is state vector of the hybrid drive system, $\mathbf{U}_{k}$ is gear shift schedule vector, $k$ is time step, the simulation time step in this work is set as $1 \mathrm{~s}$.

The aim of the optimization is to find $\mathbf{U}_{k}$ to minimize the cost function $J$, which is the sum of equivalent fuel consumption and emissions,

$$
J=\sum_{k=0}^{N-1} L\left(\mathbf{X}_{k}, \mathbf{U}_{k}\right)=\sum_{k=0}^{N-1}(1-K) m_{f, e q v, k}+K\left(A \cdot N O_{x, k}+B \cdot P M_{k}\right)
$$

where $N$ is duration of the driving cycle, $L$ is instantaneous value of the cost function including equivalent fuel consumption $m_{f, e q v, k}$ and $P M_{k}, N O_{x, k}$ of the engine at time step $k, K$ is the weighting factor of equivalent fuel economy and emission, $K \in[0,1]$. When fuel consumption is the cost function weighting factor $K=0, A$ and $B$ are weights of the emissions.

The engine fuel consumption and emissions are determined by the simplified engine model calibrated in a test bench. We can get the equivalent fuel consumption of the engine and motor with

$$
m_{f, e q v, k}=P_{i c e, k} \dot{m}_{f, i c e}+P_{e l m, k} \dot{m}_{f, e l m}
$$


where $P_{i c e, k}$ and $P_{e l m, k}$ are power output from the engine and motor at time step $k$ respectively, $\dot{m}_{f, i c e}$ and $\dot{m}_{f, e l m}$ are the equivalent fuel consumption coefficients of the engine and motor respectively. The state of engine, motor, battery and transmission should be constrained with inequality boundaries in the optimization process to make sure that each component works in the allowed situation,

$$
\begin{aligned}
\omega_{i c e \_ \text {min }} & \leqslant \omega_{i c e, k} \leqslant \omega_{i c e \_ \text {max }} \\
T_{i c e \_ \text {min }}\left(\omega_{i c e, k}\right) & \leqslant T_{i c e, k} \leqslant T_{i c e \_ \text {max }}\left(\omega_{i c e, k}\right) \\
T_{\text {ebm_min }}\left(\omega_{\text {elm }, k}, S O C_{k}\right) & \leqslant T_{\text {elm }, k} \leqslant T_{\text {elm_max }}\left(\omega_{\text {elm }, k}, S O C_{k}\right) \\
S O C_{\min } & \leqslant S O C_{k} \leqslant S O C_{\max } \\
N_{g, \min } & \leqslant N_{g, a c t} \leqslant N_{g, \max }
\end{aligned}
$$

where $\omega_{i c e, k}, T_{i c e, k}$ are engine speed and torque in step $k, \omega_{i c e \_ \text {min }}$ and $\omega_{i c e \_ \text {max }}$ are engine idle speed and maximum speed, $T_{i c e \_ \text {min }}\left(\omega_{i c e, k}\right)$ and $T_{i c e \_ \text {max }}\left(\omega_{i c e, k}\right)$ are the minimum and maximum output torque under current engine speed, $T_{\text {elm, }, k}$ is output torque of the motor, $T_{e b m \_m i n}\left(\omega_{e l m, k}, S O C_{k}\right)$ and $T_{\text {elm_max }}\left(\omega_{e l m, k}, S O C_{k}\right)$ are the minimum and maximum output torque of the motor under current motor speed and $\mathrm{SOC}, S O C_{k}$ is the current battery SOC in time $k, S O C_{\min }$ and $S O C_{\max }$ are allowed range of the battery's SOC, which is set as $0.2 \sim 0.8, N_{g, a c t}$ is current gear, $N_{g \text {,min }}$ and $N_{g \text {,max }}$ are minimum and maximum gear of the transmission.

In order to reduce frequent gear shift phenomenon, a penalty function is added as

$$
S_{k}=\phi\left|N_{g, k+1}-N_{g, k}\right|
$$

where $S_{k}$ is the cost function of frequency gear shift phenomenon, $\phi$ is penalty factor, $N_{g, k}$ and $N_{g, k+1}$ are current gear and desired gear. Equation (9) can be described as

$$
J=\sum_{k=0}^{N-1} L\left(\mathbf{X}_{k}, \mathbf{U}_{k}\right)=\sum_{k=0}^{N-1}(1-K) m_{f, e q v}+K\left(A \cdot N O_{\mathbf{x}_{k}}+B \cdot P M_{\mathbf{X}_{k}}\right)+S_{k}
$$

\section{Solving Algorithm of the Optimization Problem}

It takes a long time to solve the cost to go function by analysis or numerical method directly, because the hybrid drive system is a continuous nonlinear system. The general approach to solve the optimization problem of a continuous nonlinear system is to make the state space discrete. The state space of the hybrid drive system $\mathbf{X}_{k}$ is composed by current vehicle speed $v_{v e l, k}$, power split ratio $P S R_{k}$ and the battery $S O C_{k}$,

$$
\mathbf{x}_{k}=\left[v_{v e l, k}, P S R_{k}, S O C_{k}\right]^{\prime}
$$

These variables are discretized as below,

$$
\begin{gathered}
v_{v e l, k} \in\{0,1,2, \cdots, 99,100\} \\
P S R_{k} \in\{0,0.1,0.2,0.3,0.4,0.5,0.6,0.7,0.8,0.9,1\} \\
S_{O} C_{k} \in\{0.2,0.3,0.4,0.5,0.6,0.7,0.8\}
\end{gathered}
$$

The control variable $\mu_{i}^{*}$ is the desired gear $g_{a c t, k}$,

$$
g_{a c t, k} \in\{1,2,3,4,5\}
$$

Based on the principle of DP optimization, the problem is presented as follows: 
Step $N-1$ :

$$
J_{N-1}^{*}\left(\mathbf{X}_{N-1}\right)=\min _{u_{N-1}}\left[L\left(\mathbf{X}_{N-1}, \mathbf{U}_{N-1}\right)\right]
$$

Step $k, 0 \leqslant k<N-1$,

$$
J_{k}^{*}\left(\mathbf{X}_{k}\right)=\min _{u_{k}}\left[L\left(\mathbf{X}_{k}, \mathbf{U}_{k}\right)+J_{k+1}^{*}\left(\mathbf{X}_{k+1}\right)\right]
$$

where $J_{k}^{*}\left(\mathbf{X}_{k}\right)$ is the minimum cost function from step $k$ to the end step.

The selection of weight factor has significant influence on the cost function, and the detailed value of the cost function can be obtained with the discretized state space model Equations (19)-(21) as inputs with interpolation method. At each step of the DP algorithm, the cost function is only evaluated at the grid points, if the next state $\mathbf{X}_{k+1}$ does not fall exactly on to a grid point, then the interpolation method is used to determine the value of cost function.

Based on the simplified hybrid drive model, the global optimal strategy can be obtained by solving the recursion Equation (24) backward, with each optimization step constrained by boundary inequalities Equations (11)-(15). Although the simplified model and finite grids are utilized, the value of the cost function needs to be calculated $\left(N_{g, \max }\right)^{t}$ times if the simulation time is $t$. This will inevitably lead to dimension disaster. Two approaches are adopted in this paper to accelerate the computing speed. One is to calculate the demand power $P_{\text {wheel, req }}$ and torque $T_{\text {wheel, req }}$ of the HEV in the given driving cycle at first, the longitudinal dynamic model can be replaced by finite demand torque $T_{\text {wheel, }}$ req and rotational speed $\omega_{\text {wheel, req }}$. The other is to find the minimum value of the cost function at each gear, firstly with the fmincon function in MATLAB with the given power split strategy and map out the available real time form. The detailed process is shown in Figure 3. For a given driving cycle, the first approach is used to accelerate the searching process by converting the speed-time graph to the power-time graph. The output power flow is determined by the power split strategy based on finite state machine.

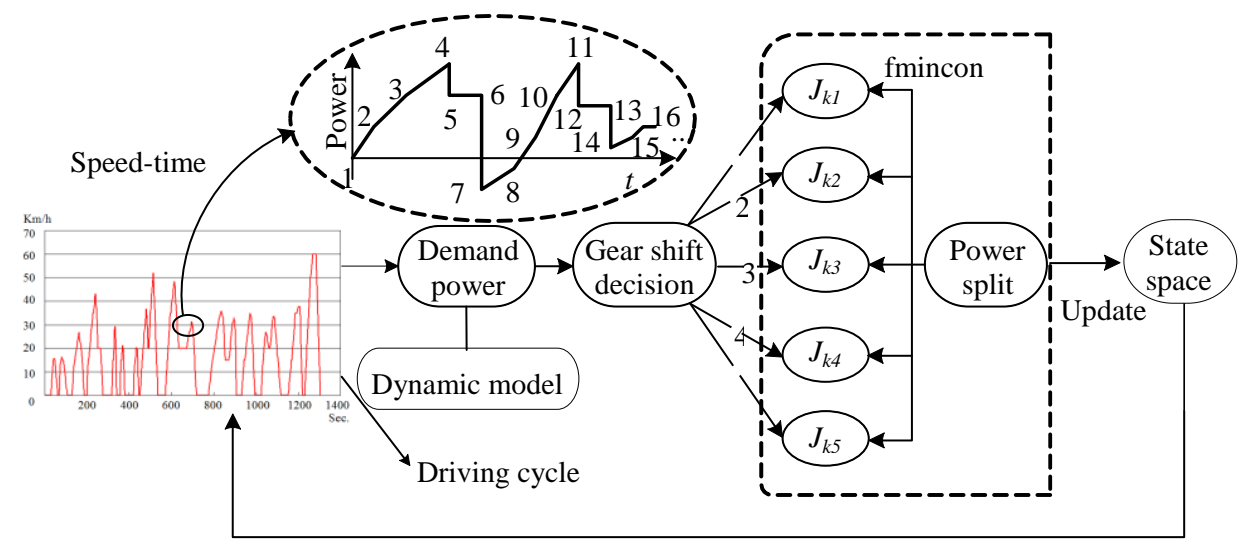

Figure 3. Schematic of the solving algorithm at time step $k$.

The different optimal gear shift schedule in a typical Chinese city driving cycle can be obtained based on a DP algorithm by adjusting the gear shift penalty factor $\phi$ in Equation (16). Figure 1 shows gear shift schedule sequences with different $\phi$, when $\phi=2.5$ the cost function is minimum and the degree of frequent gear shift phenomenon is reduced to a reasonable range. This is the obtained optimal gear shift schedule.

\section{Extraction of the Implementable Gear Shift Schedule}

A gear shift schedule that can be implemented on the real HEV is extracted based on statistical analysis of the optimal gear shifting points when $\phi=2.5$. With vehicle speed and input torque of the transmission as state variables that have great influence on shifting behavior, the obtained gear 
shift schedule is shown in Figure 4. The operating area of the AMT is divided into five parts. Each boundary of the two adjacent regions represents the optimal gear shift threshold value.

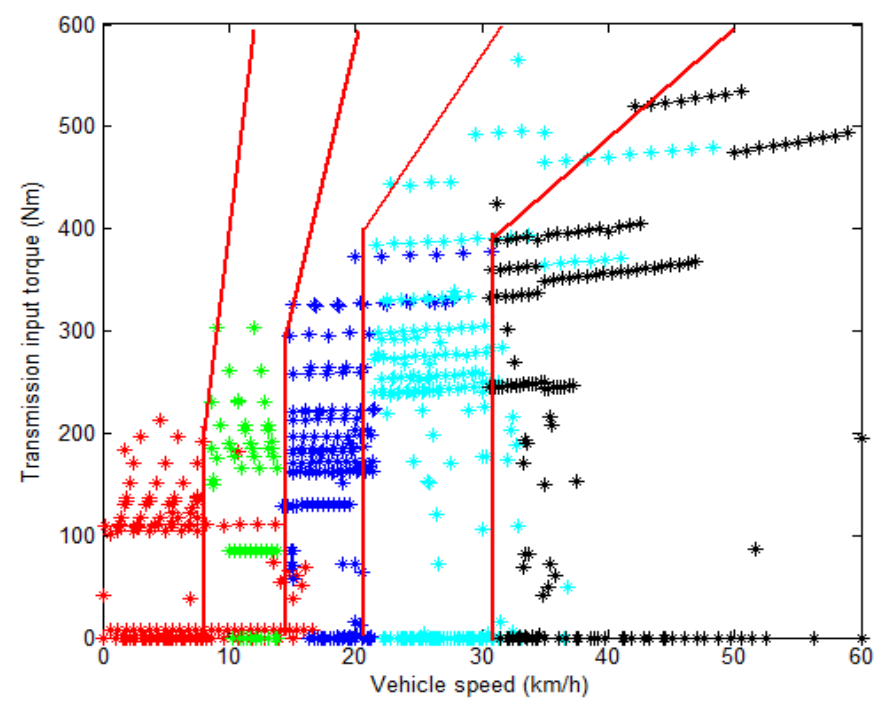

Figure 4. The extracted gear shift schedule.

According to the engineering experience, the vehicle starts with the second gear in most cases, so the designed gear shift schedule is set to start directly from the second gear. In the conventional two-parameter gear shift schedule, the downshifting point of AMT is lower than upshifting point, which is called gear shifting delay. The optimization principle of the gear shift schedule is to design the equal-delay downshifting curve according to driving experiences in a certain driving cycle. The final derived gear shift schedule is shown in Figure 5.

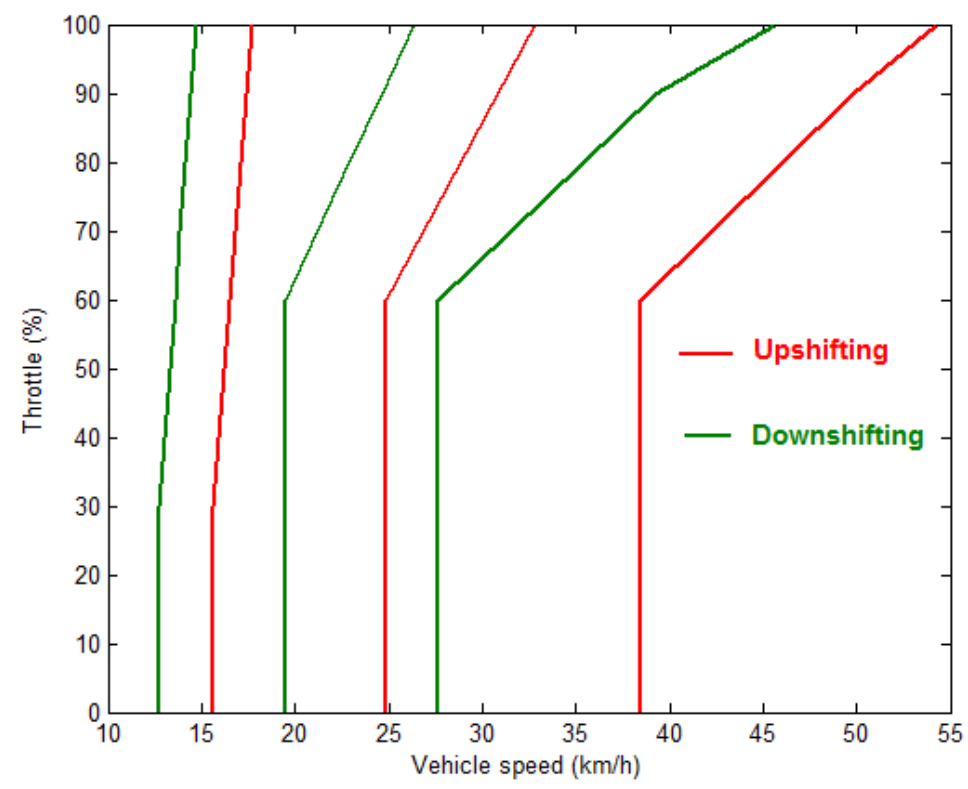

Figure 5. The optimized extracted two-parameter gear shift schedule. 


\section{Analysis of Simulation and Real Vehicle Test}

\subsection{Simulation Results}

The speed following curves of the test in typical Chinese urban driving cycle is shown in Figure 6. It is shown that the maximum deviation between simulation speed curve (green) and the desired speed curve (red) is less than $1 \mathrm{~km} / \mathrm{h}$. This deviation is primarily caused by power interruption during the gear shifting process. Due to the high efficiency of regenerative braking, the battery SOC increases from the initial value 0.5 to 0.62 , which can be observed in Figure 7. As shown in Table 1, compared with the conventional two-parameter gear shift schedule, the fuel economy of the optimized extracted gear shift schedule is obviously enhanced and even approaches the benchmark gear shift schedule obtained from DP.

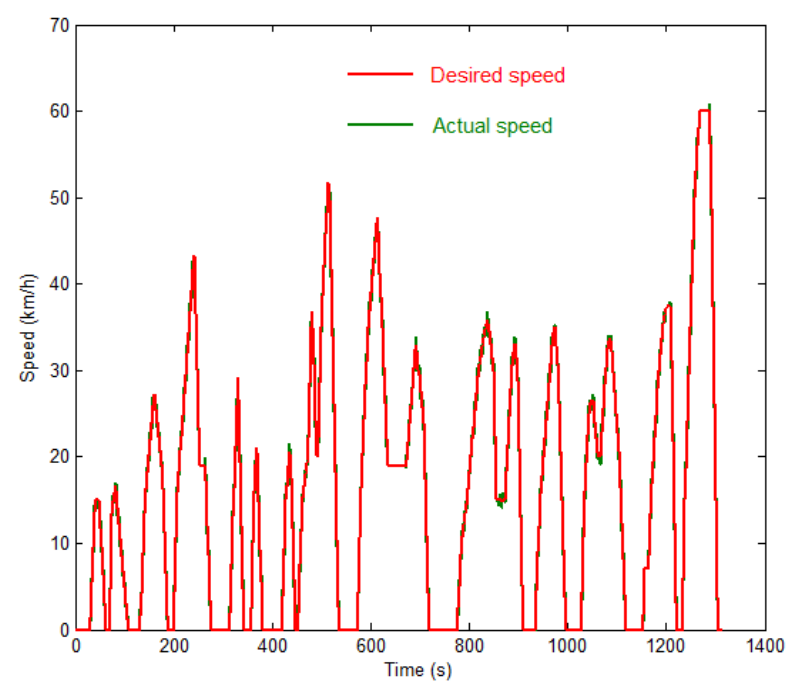

Figure 6. Speed following curve of the test.

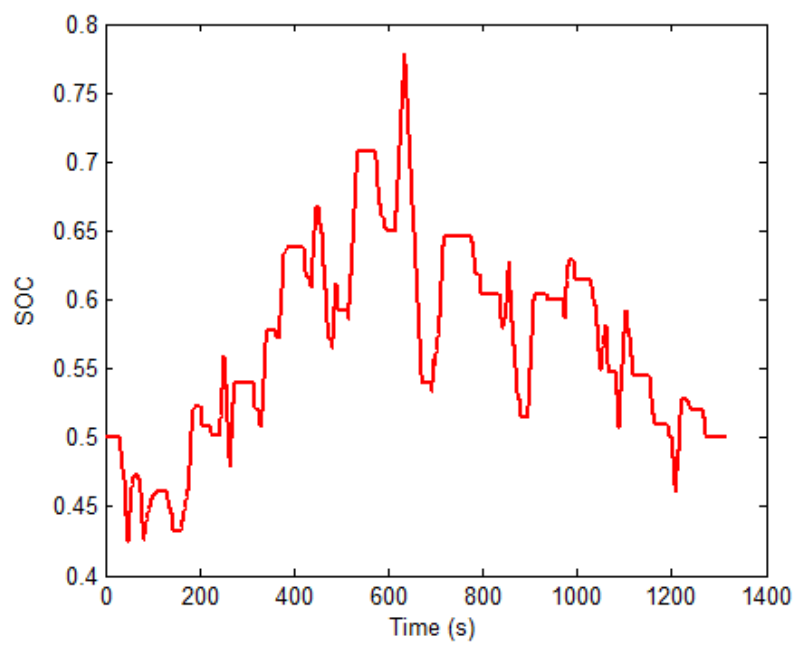

Figure 7. Simulation result of battery State Of Charge (SOC). 
Table 1. Simulation result of fuel consumption.

\begin{tabular}{lcc}
\hline \multicolumn{1}{c}{ Schedule Type } & Fuel Consumption (L/100 km) & Fuel-Efficient (\%) \\
\hline Traditional two-parameter gear shift schedule & 30.67 & $\mathrm{n} / \mathrm{a}$ \\
\hline The optimized extracted two-parameter gear shift schedule & 24.54 & 20 \\
\hline DP gear shift schedule & 23.52 & 23.3 \\
\hline
\end{tabular}

\subsection{Real Vehicle Test}

The conventional two-parameter gear shift schedule and the extracted gear shift schedule are tested and verified on a hybrid electric bus shown in Figure 8 in a typical city driving cycle. The major components' parameters of the tested HEV are listed in Table 2.
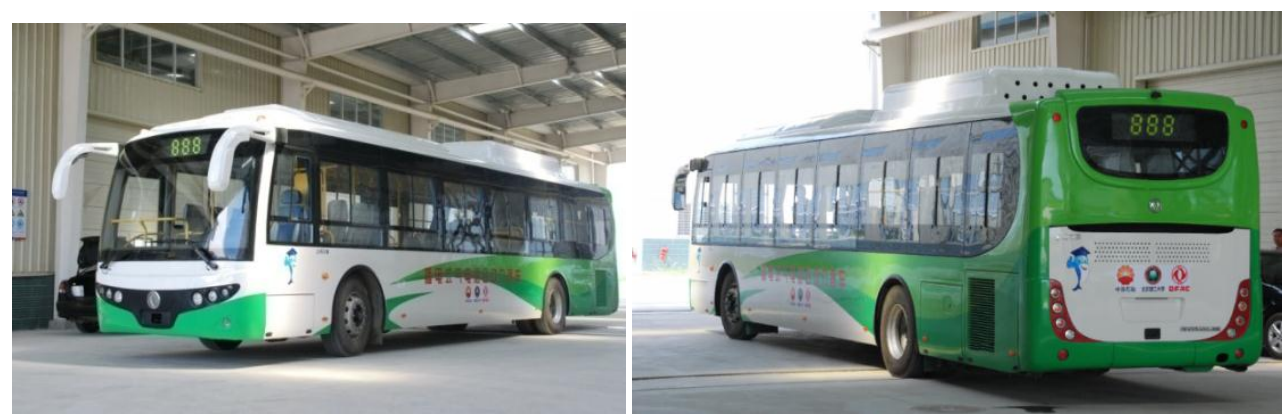

Figure 8. Real vehicle platform.

Table 2. Main parameters of hybrid electric vehicles (HEV)'s major components.

\begin{tabular}{|c|c|c|c|}
\hline Component & Specification & Value & Unit \\
\hline \multirow{6}{*}{ Engine } & Type & Nature gas & - \\
\hline & Torque & 678 & $\mathrm{~N} \cdot \mathrm{m}$ \\
\hline & Maximum Power & 172 & $\mathrm{~kW}$ \\
\hline & Number of Cylinder & 6 & - \\
\hline & Compressed Ratio & $10.5: 1$ & - \\
\hline & Service Mass & 446 & $\mathrm{~kg}$ \\
\hline \multirow{6}{*}{ Motor } & Type & Permanent magnet motor & - \\
\hline & Rated Power & $75^{\circ}$ & $\mathrm{kW}$ \\
\hline & Maximum Power & 115 & $\mathrm{~kW}$ \\
\hline & Rated Torque & 540 & $\mathrm{~N} \cdot \mathrm{m}$ \\
\hline & Base Speed & 1400 & $\mathrm{rev} / \mathrm{min}$ \\
\hline & Maximum Speed & 3200 & $\mathrm{rev} / \mathrm{min}$ \\
\hline Transmission & Gear ratios & $7.05 / 3.85 / 2.52 / 1.59 / 1.00$ & - \\
\hline Final Reducer & Gear ratio & 6.167 & - \\
\hline \multirow{4}{*}{ Battery } & Battery Pack Voltage & 288 & $\mathrm{~V}$ \\
\hline & Battery capacity & 8 & $\mathrm{Ah}$ \\
\hline & Number of cells & 90 & - \\
\hline & Voltage of cell & 3.2 & V \\
\hline \multirow{5}{*}{ Vehicle Body } & Vehicle Mass & 11,700 & $\mathrm{~kg}$ \\
\hline & Dynamic Tire Radius & 0.478 & $\mathrm{~m}$ \\
\hline & Air Density & 1.2 & $\mathrm{~kg} / \mathrm{m}^{3}$ \\
\hline & Front area of vehicle & 6 & $\mathrm{~m}^{2}$ \\
\hline & Aerodynamic drag coefficient & 0.7 & - \\
\hline
\end{tabular}


Considering the fact that the driving profile of the real hybrid electric bus is consistent with typical Chinese urban driving conditions. The real vehicle test results and the simulation results demonstrate a high degree of agreement which can be seen from Table 3 (deviation no more than $5 \%$ ).

Table 3. Fuel consumption in simulation and real vehicle platform.

\begin{tabular}{lccc}
\hline \multicolumn{1}{c}{ Schedule Type } & $\begin{array}{c}\text { Simulation Results } \\
(\mathbf{L} / \mathbf{1 0 0} \mathbf{~ k m})\end{array}$ & $\begin{array}{c}\text { Real Vehicle Results } \\
(\mathbf{L} / \mathbf{1 0 0} \mathbf{~ k m})\end{array}$ & Deviation (\%) \\
\hline $\begin{array}{l}\text { Conventional two parameters } \\
\text { gear shift schedule }\end{array}$ & 30.67 & 29.5 & 3.8 \\
\hline $\begin{array}{l}\text { The optimized two-parameter } \\
\text { gear shift schedule }\end{array}$ & 24.54 & 23.9 & 2.6 \\
\hline
\end{tabular}

\section{Conclusions}

In this paper, a powertrain model and longitudinal dynamics model of a HEV is developed to optimize the best economic gear shift schedule based on the DP method. The excellent result obtained by DP is used as a reference to see the potential room for improvement and is used as a benchmark to evaluate other gear shift schedules. After that, a two-parameter gear shift schedule that can be used on a real vehicle is extracted from the optimal gear shift schedule sequence and is optimized based on engineering experience. Simulation and real vehicle test show that the optimized extracted two-parameter gear shift schedule can clearly improve the fuel economy of the HEV compared with the conventional two-parameter shift schedule, and can even approach the result obtained by DP. The design method can also be applied to the design gear shift schedule for other kinds of vehicles equipped with different kinds of automatic transmission.

Acknowledgments: This research is partially supported by the National Natural Science Foundation of China (Grant No.51505029).

Author Contributions: All authors contributed to this work in collaboration. Wenchen Shen and Huilong Yu validated the hybrid electric powertrain model, implemented the proposed strategy and wrote the paper together, they contributed equally in this work; Yuhui Hu provided important help with the experimental setup; Junqiang $\mathrm{Xi}$ gave many enlightenments during the final achievement gathering.

Conflicts of Interest: The authors declare no conflict of interest.

\section{Abbreviations}

The following abbreviations are used in this manuscript:

$\begin{array}{ll}\text { HEV } & \text { Hybrid Electric Vehicle } \\ \text { AMT } & \text { Automated Mechanical Transmission } \\ \text { DP } & \text { Dynamic Programming } \\ \text { SOC } & \text { State of Charge }\end{array}$

\section{References}

1. Sun, Z.; Hebbale, K. Challenges and Opportunities in Automotive Transmission Control. In Proceedings of the 2005 American Control Conference, Portland, OR, USA, 8-10 June 2005; pp. 3284-3289.

2. Dorri, M.; Shamekhi, A.H. Design and optimization of a new control strategy in a parallel hybrid electric vehicle in order to improve fuel economy. Proc. Inst. Mech. Eng. Part D J. Automob. Eng. 2011, 225, 747-759. [CrossRef]

3. Lee, H.; Kirn, H. Improvement in fuel economy for a parallel hybrid electric vehicle by continuously variable transmission ratio control. Proc. Inst. Mech. Eng. Part D J. Automob. Eng. 2005, 219, 43-51. [CrossRef]

4. Pandian, S.; Gokhale, S.; Ghoshal, A.K. Evaluating effects of traffic and vehicle characteristics on vehicular emissions near traffic intersections. Transp. Res. Part D Transp. Environ. 2009, 14, 180-196. [CrossRef] 
5. Stevanovic, A.; Stevanovic, J.; Zhang, K.; Batterman, S. Optimizing traffic control to reduce fuel consumption and vehicular emissions. Transp. Res. Rec. J. Transp. Res. Board 2009, 2128, 105-113. [CrossRef]

6. Chen, K.S.; Wang, W.C.; Chen, H.M.; Lin, C.F.; Hsu, H.C.; Kao, J.H.; Hu, M.T. Motorcycle emissions and fuel consumption in urban and rural driving conditions. Sci. Total Environ. 2003, 312, 113-122. [CrossRef]

7. Tong, H.Y.; Hung, W.T.; Cheung, C.S. On-road motor vehicle emissions and fuel consumption in urban driving conditions. J. Air Waste Manag. Assoc. 2000, 50, 543-554. [CrossRef] [PubMed]

8. Wu, C.; Zhao, G.; Ou, B. A fuel economy optimization system with applications in vehicles with human drivers and autonomous vehicles. Transp. Res. Part D Transp. Environ. 2011, 16, 515-524. [CrossRef]

9. Wang, W.; Xi, J.; Chen, H. Modeling and recognizing driver behavior based on driving data: A survey. Math. Probl. Eng. 2014, 2014. [CrossRef]

10. Anlin, G. Design and Theory of Vehicle Automatic Gear Shifting; China Machine Press: Beijing, China, 1993.

11. Liu, N. Research on Shift Schedule of Hybrid bus; Jilin University: Changchun, China, 2007.

12. Yu, H.; Xi, J.; Chen, Y. Research on Shift Schedule of Hybrid Bus Based on Dynamic Programming Algorithm. In Proceedings of the 2012 15th International IEEE Conference on Intelligent Transportation Systems (ITSC), Anchorage, AK, USA, 16-19 September 2012; pp. 1067-1071.

13. Ngo, V.; Hofman, T.; Steinbuch, M.; Serrarens, A. Optimal control of the gearshift command for hybrid electric vehicles. IEEE Trans. Veh. Technol. 2012, 61, 3531-3543. [CrossRef]

14. Hofman, T.; Steinbuch, M.; van Druten, R.; Serrarens, A.F.A. Design of cvt-based hybrid passenger cars. IEEE Trans. Veh. Technol. 2009, 58, 572-587. [CrossRef]

15. Hofman, T.; Steinbuch, M.; van Druten, R.; Serrarens, A. Rule-based energy management strategies for hybrid vehicles. Int. J. Electr. Hybrid Veh. 2007, 1, 71-94. [CrossRef]

16. Koot, M.; Kessels, J.T.B.A.; de Jager, B.; Heemels, W.P.M.H.; van den Bosch, P.P.J.; Steinbuch, M. Energy management strategies for vehicular electric power systems. IEEE Trans. Veh. Technol. 2005, 54, 771-782. [CrossRef]

17. Sciarretta, A.; Guzzella, L. Control of hybrid electric vehicles. IEEE Control Syst. 2007, 27, 60-70. [CrossRef]

18. Sciarretta, A.; Back, M.; Guzzella, L. Optimal control of parallel hybrid electric vehicles. IEEE Trans. Control Syst. Technol. 2004, 12, 352-363. [CrossRef]

19. Ambühl, D.; Sundström, O.; Sciarretta, A.; Guzzella, L. Explicit optimal control policy and its practical application for hybrid electric powertrains. Control Eng. Pract. 2010, 18, 1429-1439. [CrossRef]

20. Xiong, W.; Zhang, Y.; Yin, C. Optimal energy management for a series-parallel hybrid electric bus. Energy Convers. Manag. 2009, 50, 1730-1738. [CrossRef]

21. Sundstrom, O.; Soltic, P.; Guzzella, L. A transmission-actuated energy-management strategy. IEEE Trans. Veh. Technol. 2010, 59, 84-92. [CrossRef]

22. Casavola, A.; Prodi, G.; Rocca, G. Efficient gear shifting strategies for green driving policies. In Proceedings of the 2010 American Control Conference, Baltimore, MD, USA, 30 June-2 July 2010; IEEE: New York, NY, USA, 2010; pp. 4331-4336.

23. Wang, W.; Wang, Q.; Zeng, X. Automated Manual Transmission Shift Strategy for Parallel Hybrid Electric Vehicle; SAE International: New York, NY, USA, 2009.

24. Qin, G.; Ge, A.; Lee, J.-J. Knowledge-based gear-position decision. IEEE Trans. Intell. Transp. Syst. 2004, 5, 121-125. [CrossRef]

25. Isermann, R. Mechatronic Systems: Fundamentals; Springer London: London, England, 2007.

26. Bertsekas, D.P. Dynamic Programming and Optimal Control: Approximate Dynamic Programming; Athena Scientific: New Hampshire, NH, USA, 2012.

27. Zhu, Z.Q.; Pang, Y.; Chen, J.T.; Xia, Z.P.; Howe, D. Influence of Design Parameters on Output Torque of Flux-Switching Permanent Magnet Machines. In Proceedings of the 2008 IEEE Vehicle Power and Propulsion Conference, VPPC '08, Harbin, China, 3-5 September 2008; pp. 1-6.

28. Hentunen, A.; Lehmuspelto, T.; Suomela, J. Time-domain parameter extraction method for théveninequivalent circuit battery models. IEEE Trans. Energy Convers. 2014, 29, 558-566. [CrossRef]

(C) 2016 by the authors; licensee MDPI, Basel, Switzerland. This article is an open access article distributed under the terms and conditions of the Creative Commons by Attribution (CC-BY) license (http:/ / creativecommons.org/licenses/by/4.0/). 